\title{
Anesthetic efficacy and physiological responses of clove oil on juvenile and adult red spotted grouper, Epinephelus akarra
}

\author{
In-Seok Park ${ }^{1,4^{*}}$, Tae Ho Lee ${ }^{1}$ and Sang Gu Lim²,3
}

\begin{abstract}
The main objective of this study was to provide anesthetic criteria of clove oil for an effective manipulation and transportation of red spotted grouper, Epinephelus akaara. When anesthesia temperature $\left(20,24\right.$, and $\left.28{ }^{\circ} \mathrm{C}\right)$ and concentration of clove oil $(25,50$, and 75 ppm) were increased, the anesthesia and recovery time decreased and tended to be similar to each other between juvenile and adult. Also, as the temperature and concentration increased, the ratio of exposure time and recovery time between juvenile and adult were decreased. When plasma cortisol concentrations were compared for $48 \mathrm{~h}$ after anesthesia with $50 \mathrm{ppm}$ of clove oil, both the juvenile and adult fish grew up to $12 \mathrm{~h}$; however, thereafter decreased and there was no significant difference from control at $48 \mathrm{~h}$.
\end{abstract}

Keywords: Clove oil, Epinephelus akaara, Plasma cortisol

\section{Background}

Anesthesia is generally used to attenuating stress caused by artificial handling, transportation, tagging, and injection because it lowers the metabolic rate due to sedative effect during the delicate handling period (Schreck 1982; Summerfelt and Smith 1990). Handling and transporting fish in a container and transport car is stressful to fish. They can lead to physiological stress, physical injury, and death (Marking and Meyer 1985). Therefore, many stress-relief methods have been attempted in the aquaculture society. Among different methods, anesthesia is found to be appropriate for handling fish. Effective anesthesia can alleviate plasma glucose and cortisol (Mommsen et al. 1999) and immobilize fish during manipulation. In addition, they are non-toxic to handlers. Moreover, it is simple to use. Despite the positive effects of anesthesia, inappropriate application of anesthetics may lead to unintended results. It might have adverse effects such as creating more stress, eliciting negative metabolic responses, and even leading to death.

\footnotetext{
* Correspondence: ispark@kmou.ac.kr

${ }^{1}$ Division of Marine Bioscience, College of Ocean Science and Technology, Korea Maritime and Ocean University, Busan 606-791, South Korea

${ }^{4}$ Division of Marine Environment and Bioscience, College of Ocean Science and Technology, Korea Maritime University, 727 Taejong-ro, Yeong do-gu, Busan 49112, South Korea

Full list of author information is available at the end of the article
}

Therefore, determining the suitable concentrations of anesthetic is very important. Various responses of anesthetic effect have been specified previously (Summerfelt and Smith 1990), including anesthetic condition such as exposure time and recovery time. Many anesthetics have been used. Clove oil has been recently spotlighted as a useful fish anesthetic. Eugenol (4-allyl-2-methoxyphenol) is the active ingredient of clove oil. It is also non-toxic to handlers. Listed by the US Food and Drug Administration (1978), it has been experimented in fish at different stage including fry to adult fish. It is an excellent sedative anesthetic for long period transportation.

Red spotted grouper, Epinephelus akaara, is a species of fish in the order of Perciformes and Family of Serranidae (Brais 1987). Red spotted grouper is a reef fish. It inhabits in tropical and sub-tropical regions of Southeast Asia, especially in the China and Southern parts of Korea which have early life history. It is also registered as an endangered species (Brais 1987; IUCN 2016). This grouper fish is protogynous hermaphrodite. It can change sex from female to male (Brais 1987). Most studies have been limited to the only stages and conditions of this fish. This study focused on various temperatures, two stages (larvae and adult), and different doses/concentrations of clove oil. The main objective of this study 
was to provide anesthetic criteria of clove oil for an effective manipulation and transportation of red spotted grouper.

\section{Materials and methods}

Experiments were conducted at the Future Aquaculture Research Center in Jeju, South Korea. Ten juvenile specimens (standard length $9.1 \pm 1.78 \mathrm{~cm}$, body weight 14.3 $\pm 4.21 \mathrm{~g}$; mean $\pm \mathrm{SD})$ and ten adult specimens (35.1 \pm $5.92 \mathrm{~cm}, 1044.5 \pm 149.63 \mathrm{~g}$ ) were individually exposed to each anesthetic concentration. For sufficient adaptation, fish samples were acclimated for 1 week at different water temperature $\left(20,24\right.$, and $\left.28^{\circ} \mathrm{C}\right)$ with filtration and aeration. All fish samples were starved for $24 \mathrm{~h}$ prior to experiments. Water quality parameters during the experiment were tested daily and maintained as followed: $\mathrm{pH} 7.5 \pm 0.07$, salinity $31.2 \pm 0.17$, and dissolved oxygen $7.1 \pm 0.35$. Anesthetic used in this study was clove oil (82-87\% eugenol, Sigma-Aldrich, St. Louis, MO, USA). Clove oil is poorly mixable with water. Therefore, it was dissolved in 95\% ethanol (Sigma-Aldrich, St. Louis, MO, USA) at a ratio of 1:10. To determine the anesthetic dose, different concentrations of clove oil $(25,50$, and $75 \mathrm{ppm})$ were exposed to fish at different water temperatures $\left(20,24\right.$, and $\left.28{ }^{\circ} \mathrm{C}\right)$. Each juvenile fish was transferred from a stock tank to anesthetic-containing aquarium $(20 \mathrm{~L})$. Anesthetized sample was then transferred to a sea water tank containing $(20 \mathrm{~L}$ with sufficiently aeration) for recovery. Individual adult fish was transferred to anesthetic-containing aquarium (100 L). Anesthetized individual sample was then transferred to a sea water tank containing (100 L) for recovery. Stages of anesthesia and recovery response are shown in Table 1. Exposure time (anesthesia time) and recovery time were recorded using a stopwatch. To define the stress response of experimental samples to anesthetic exposure, blood samples were obtained from ten randomly selected fish. In order to compare the blood plasma cortisol concentrations over time for $48 \mathrm{~h}$ at the same concentration (clove oil $50 \mathrm{ppm}$ ) of juvenile and adult fish, seven groups were established: control, no exposure to anesthetic; shortly after anesthesia: $1,6,12,24$, and $48 \mathrm{~h}$. Blood was centrifuged at $200 \times g$ for $10 \mathrm{~min}$ and stored at $-80{ }^{\circ} \mathrm{C}$ freezer (Nihon Freezer, Japan) until analysis. Cortisol concentration in $50 \mu$ l samples was measured using a cortisol radioimmunoassay kit (Coat-A-Count TKCO Cortisol RIA Kit; DPC, USA). Two-way analysis of variance (ANOVA) and Duncan's multiple range test (Duncan 1955) were used to determine the significance of difference among means of treatments using SPSS software (SPSS 9.0, SPSS Inc., USA).

\section{Results and discussion}

Different clove oil concentrations and temperatures affected the exposure time and recovery time for both juvenile and adult red spotted grouper. All experimental fish samples survived after being exposed to the anesthetic during the experiment. As shown in Table 2, exposure times of all samples were decreased when the concentration of clove oil was increased. Regarding the exposure time of juvenile and adult at $20{ }^{\circ} \mathrm{C}$, juvenile samples were anesthetized 1.4-1.7 times faster than

Table 1 Stages of anesthesia and recovery of red spotted grouper, Epinephelus akaara, after exposing to clove oil*

\begin{tabular}{ll}
\hline Stage & Characteristic behavior \\
\hline A1 & Anesthesia \\
A2 & Sormal swimming; operculum movement and normal general movement \\
A3 & Partial loss of equilibrium; swimming erratically \\
A4 & Complete loss of equilibrium; swimming perfectly inside-out; pectoral fin, pelvic fin, and dorsal fin movement stop \\
A5 & Little sedation; anal fin and tail fin movement stop \\
A6 & Perfect sedation; only operculum movement \\
A7 & Operculum movement ceased \\
& Recovery \\
R1 & Resume operculum movement \\
R2 & Preferential movement of pectoral fin and tail fin \\
R3 & Dorsal fin, pelvic fin, and anal fin movement \\
R4 & Swimming perfectly inside-out \\
R5 & Swimming erratically; redressing the balance \\
R6 & Normal swimming; responsiveness to visual stimuli
\end{tabular}

*Modified from Summerfelt and Smith (1990) 
Table 2 Effects of different clove oil concentrations and temperatures on anesthesia time and recovery time of juvenile and adult red spotted grouper, Epinephelus akaara*

\begin{tabular}{|c|c|c|c|c|c|}
\hline \multirow[t]{3}{*}{ Temperature $\left({ }^{\circ} \mathrm{C}\right)$} & \multirow[t]{3}{*}{ Dose (ppm) } & \multicolumn{4}{|c|}{ Time (sec) } \\
\hline & & \multicolumn{2}{|c|}{ Juvenile } & \multicolumn{2}{|c|}{ Adult } \\
\hline & & Exposure & Recovery & Exposure & Recovery \\
\hline \multirow[t]{3}{*}{20} & 25 & $151 \pm 17.2^{c}$ & $291 \pm 23.5^{b}$ & $255 \pm 15.4^{c}$ & $280 \pm 21.7^{b}$ \\
\hline & 50 & $103 \pm 10.4^{b}$ & $273 \pm 17.3^{b}$ & $163 \pm 11.7^{b}$ & $271 \pm 19.3^{b}$ \\
\hline & 75 & $75 \pm 10.3^{a}$ & $238 \pm 16.5^{\mathrm{a}}$ & $107 \pm 9.5^{a}$ & $243 \pm 11.5^{a}$ \\
\hline \multirow[t]{3}{*}{24} & 25 & $138 \pm 9.3^{c}$ & $288 \pm 21.8^{b}$ & $221 \pm 15.6^{c}$ & $257 \pm 20.3^{b}$ \\
\hline & 50 & $91 \pm 10.1^{b}$ & $256 \pm 18.1^{a}$ & $123 \pm 9.3^{b}$ & $232 \pm 17.2^{\mathrm{a}}$ \\
\hline & 75 & $67 \pm 9.4^{a}$ & $241 \pm 15.7^{\mathrm{a}}$ & $88 \pm 6.2^{a}$ & $214 \pm 15.1^{a}$ \\
\hline \multirow[t]{3}{*}{28} & 25 & $126 \pm 10.5^{c}$ & $267 \pm 24.9^{b}$ & $153 \pm 10.5^{c}$ & $248 \pm 21.5^{b}$ \\
\hline & 50 & $83 \pm 11.2^{b}$ & $273 \pm 20.1^{b}$ & $94 \pm 11.2^{b}$ & $219 \pm 16.8^{b}$ \\
\hline & 75 & $59 \pm 7.9^{\mathrm{aA}}$ & $229 \pm 12.1^{a}$ & $71 \pm 9.9^{a}$ & $83 \pm 9.1^{a}$ \\
\hline
\end{tabular}

*Each value is mean \pm standard deviation of triplicate independent experiments $(n=10)$. Different small letters indicate significant differences for the different clove oil dose at the same water temperature $(P<0.05)$, the same superscript letter are not significantly different $(P>0.05)$

adult samples. At $24{ }^{\circ} \mathrm{C}$, juvenile samples were anesthetized 1.3-1.6 times faster than adult samples. At $28{ }^{\circ} \mathrm{C}$, juvenile samples were anesthetized 1.1-1.2 times faster than adult samples. When water temperature was further increased, the anesthesia time tended to be similar to each other between juvenile and adult.

Compared the water temperature in the anesthetic as temperature rose to $28{ }^{\circ} \mathrm{C}\left(20,24\right.$, and $\left.28{ }^{\circ} \mathrm{C}\right)$, a time of 1.2-1.3 times was decreased in all anesthetic concentration. When results were compared between low concentration and high concentration of clove oil, anesthesia time for both juvenile and adult samples at $75 \mathrm{ppm}$ was shortened by more than 2 fold compared to that at $25 \mathrm{ppm}$, while results at $50 \mathrm{ppm}$ were closer to those at $75 \mathrm{ppm}$ than that those at $25 \mathrm{ppm}$. Recovery time for juvenile and adult showed the similar tendency at all anesthesia temperatures (20, 24, and $28{ }^{\circ} \mathrm{C}$ ). When the concentration of clove oil was increased (25 to $75 \mathrm{ppm}$ ), the recovery time was shorter. Thus, the lowest concentration needed the longest anesthesia time and recovery time, while the highest concentration had the fastest anesthesia time and the recovery time. When the recovery time at different water temperatures was compared, juvenile samples took 1.1-1.3 times longer recovery time than adult samples at all temperatures.

According to Park et al. (2008) and Santos et al. (2015), fish samples are affected by both temperature and clove oil concentration. Santos et al. (2015) have determined the effect of different anesthetics (MS-222, 2-phenoxyethanol, clove oil, and benzocaine) on marbled rabbitfish, Siganus rivulatus, at different water temperatures. Marbled rabbitfish had the fastest anesthesia time at high temperature $\left(30{ }^{\circ} \mathrm{C}\right)$ regardless of which anesthetic was used. Anesthesia time at high temperature and concentrations attributed to exposure time and recovery time of kelp grouper, E. bruneus, which showed different tendency of recovery time compared to red spotted grouper. In general, high anesthetic concentration requires a longer recovery time (Simoes et al. 2011; Tarkhani et al. 2016). For Nile tilapia (Oreochromis niloticus), after exposing to various concentrations (50 to $100 \mathrm{ppm}$ ) of clove oil, recovery time from high concentration exposure is more than two times longer compared that from low concentration exposure (Simoes et al. 2011 Tarkhani et al. (2016) have found that, as the weight of flowerhorn, Amphilophus labiatus $\times$ Amphilophus trimaculatus is increased (12 to $53 \mathrm{~g}$ ), eugenol concentration needed for anesthesia is increased (25 to 200 ppm). Ghanawi et al. (2013) have studied spinefoot; Siganus rivulatus were experimented at anesthetized at clove oil (40, 70 and $100 \mathrm{ppm})$, they were recorded similar tendency to red spotted grouper. Therefore, when water temperature or the concentration of clove oil is changed, the anesthesia time and recovery time might be different.

Regarding the stress responses based on plasma cortisol of time after being exposed to clove oil, results of plasma cortisol concentrations in red spotted grouper with elapsed time are shown in Fig. 1. Plasma cortisol concentrations at each temperature was increased as time elapsed, reaching the peak level at $12 \mathrm{~h}$ after exposure to clove oil. They were then decreased from 12 to $48 \mathrm{~h}$ after exposure to clove oil in both juvenile and adult samples. They were then recovered until $48 \mathrm{~h}$. Plasma cortisol concentrations at high water temperatures $\left(24\right.$ and $28{ }^{\circ} \mathrm{C}$ ) were slightly but significantly $(P<0.05)$ higher than those at low water temperature $\left(20^{\circ} \mathrm{C}\right)$ in all samples. 


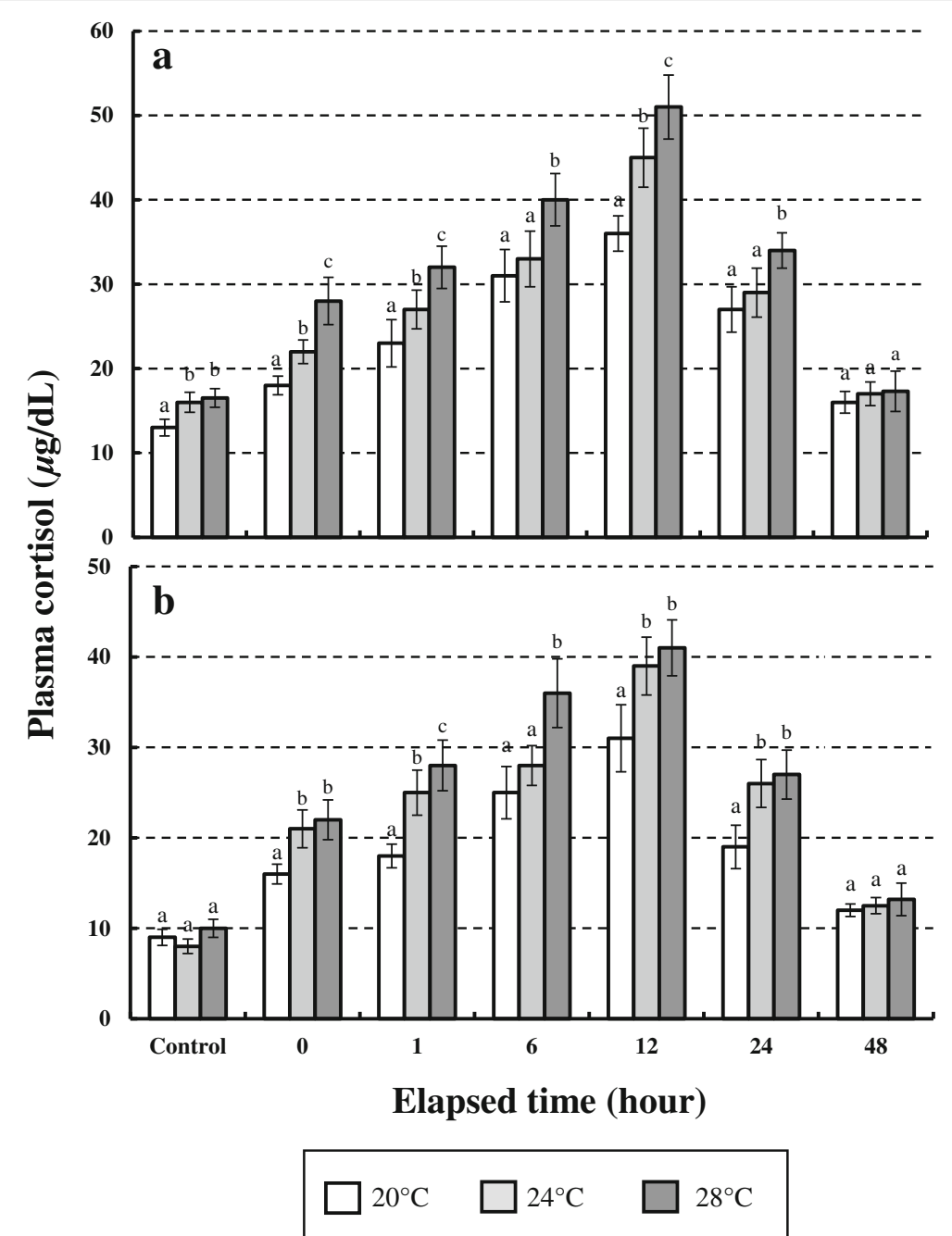

Fig. 1 Variations in blood plasma cortisol concentrations in juvenile and adult red spotted grouper, Epinephelus akaara, after exposure to 50 ppm clove oil for $48 \mathrm{~h}$ in various temperatures. Values are means \pm SE of triplicate experiments $(n=10)$. a Juvenile (means BL, $10.4 \pm 3.8 \mathrm{~cm}) ; \mathbf{b}$ adult (means $B L, 35.6 \pm 4.3 \mathrm{~cm})$. Different letters on error bars are significantly different among different elapsed time points in anesthesia groups $(P<0.05)$

Plasma cortisol can be an indicator of stress response in fish subjected to various harsh environment. It is related to metabolism and movement (Mommsen et al. 1999). Plasma cortisol level can be influenced by handling, air exposure, and sampling. Thus, determining cortisol concentrations is very important. Park et al. (2008) have reported that, when kelp grouper are exposed to clove oil, plasma cortisol is increased until $12 \mathrm{~h}$ and decreased thereafter. Figure 2 can be used to understand the relationship between exposure time and recovery time. Figure 2 was modeled by a division of exposure time to recovery time. It can be used to determine the effects of different temperatures, anesthetic concentrations, and fish stages on exposure time and recovery time. As shown in Fig. 2, juvenile and adult had the similar ratio of exposure time to recovery time at each temperature. The time ratio at $28{ }^{\circ} \mathrm{C}$ was slightly larger than that at other temperatures at 25 or $50 \mathrm{ppm}$. Overall, juvenile samples had larger time ratio than adult samples at all temperatures and concentrations. Based on the time ratio reported by Park et al. (2008), kelp grouper showed a smaller value than red spotted grouper, suggesting that red spotted grouper might be more sensitive to clove oil anesthesia than kelp grouper.

Suitable anesthetic concentrations have been used to measuring the exposure time within $3 \mathrm{~min}$ and recovery time within $10 \mathrm{~min}$ (Park et al. 2003). Clove oil concentrations of that experiment did not cause injury or death. They were harmless to handler and fish samples. In this study, we used the effect of different water temperatures 


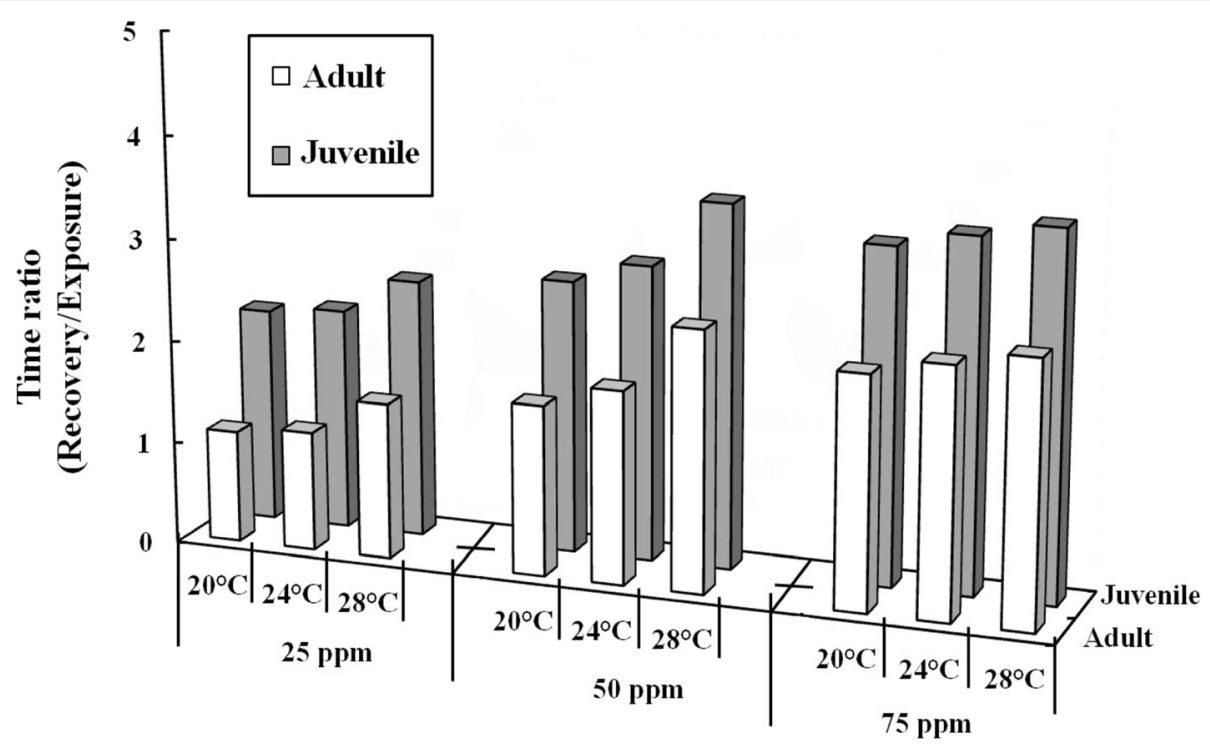

Clove oil dose (ppm)

Fig. 2 Effect of clove oil dose and water temperature on recovery time/anesthetic time ratio in juvenile and adult red spotted grouper, Epinephelus akaara. Values are means \pm SE of triplicate experiments $(n=10$ ). Juvenile (means BL, $10.4 \pm 3.8 \mathrm{~cm}$ ); adult (means BL, $35.6 \pm 4.3 \mathrm{~cm}$ )

on anesthesia time and recovery time in juvenile and adult red spotted grouper. However, effects of salinity variations and different anesthetics on red spotted grouper are also important. Such studies should be performed in the future. Nonetheless, our results may provide useful information for performing successful anesthetic experiment using red spotted grouper.

\section{Conclusions}

The effect of clove oil as an anesthetic plays a sufficient role in the red spotted grouper, Epinephelus akaara. As the water temperature and concentration increased, both the anesthetic time reduced and the recovery time increased. Plasma cortisol, which was measured to examine the stress response, was increased up to $12 \mathrm{~h}$ after anesthesia but decreased thereafter, which was almost the similar as that of the control group at $48 \mathrm{~h}$.

\section{Abbreviation}

Hrs: hours

\section{Acknowledgements}

The authors thank the technical staff of the Future Aquaculture Research Center, NIFS, South Korea, and the Laboratory for Fishery Genetics and Breeding Sciences at Korea Maritime and Ocean University, South Korea, for their helpful support, and the anonymous reviewers who greatly improved the quality of this manuscript. We appreciate for research opportunity in this study and comply with the Current Laws of Korea (Ordinance of Agriculture, Food and Fisheries, no. 1--the Law Regarding Experimental Animals, no. 9932) and the Ethical Guidelines of Korea Maritime and Ocean University, South Korea.

\section{Funding}

This research was supported by a research grant (R2017037) from Future Aquaculture Research Center, National Fisheries Research and Development Institute, South Korea.

\section{Authors' contributions}

THL and ISP designed the overall plan of the experiment and drafted this manuscript. THL and SGL conducted the whole part of the experiment, for example, collected blood samples of anesthetic fishes. All authors read and approved the manuscript.

Ethics approval and consent to participate

Not applicable.

\section{Competing interests}

The authors declare that they have no competing interests.

\section{Publisher's Note}

Springer Nature remains neutral with regard to jurisdictional claims in published maps and institutional affiliations.

\section{Author details}

'Division of Marine Bioscience, College of Ocean Science and Technology, Korea Maritime and Ocean University, Busan 606-791, South Korea.

${ }^{2}$ Aquafeed Research Center, National Institute of Fisheries Science, Pohang 37517, South Korea. ${ }^{3}$ Future Aquaculture Research Center, National Institute of Fisheries Science (NIFS), Jeju 690-192, South Korea. ${ }^{4}$ Division of Marine Environment and Bioscience, College of Ocean Science and Technology, Korea Maritime University, 727 Taejong-ro, Yeong do-gu, Busan 49112, South Korea.

Received: 23 October 2017 Accepted: 25 May 2018

Published online: 22 July 2018

\section{References}

Brais. Grouper abstracts. Tigbauan: SEAFDEC Aquaculture Department; 1987. p. 95. Duncan DB. Multiple range and multiple $F$ tests. Biometrics. 1955;11:1-42.

Ghanawi J, Monzer S, Saoud IP. Anaesthetic efficacy of clove oil, benzocaine, 2phenoxyethanol and tricaine methanesulfonate in juvenile marbled spinefoot, Siganus rivulatus. Aquac Res. 2013;44:359-66.

IUCN (2016) IUCN Red List of Threatened Species. http://www.iucnredlist.org/ details/43974/0. Downloaded on 09 March 2016.

Marking LL, Meyer FP. Are better anesthetics needed in fisheries? Fisheries. 1985; 10:2-5. 
Mommsen TP, Vijayan MM, Moon TW. Cortisol in teleosts: dynamics, mechanisms of action and metabolic regulation. Rev Fish Biol Fish. 1999;9:211-68.

Park I-S, Jo JH, Lee SJ, Kim YA, Kim KE, Hur JW, Yoo JS, Song YC. Anaesthetic effect of lidocaine hydrochloride-sodium bicarbonate and MS-222 on the greenling (Hexagrammos otakii). Journal of the Korean Fisheries Society. 2003;36:449-53.

Park MO, Hur WJ, Im SY, Seol DS, Lee JH, Park I-S. Anaesthetic efficacy and physiological responses to clove oil-anaesthetized kelp grouper Epinephelus bruneus. Aquac Res. 2008:39:877-84.

Santos S, Ghanawi J, Saoud IP. Effects of water temperature and body weight on anaesthetic efficiency in marbled rabbitfish, Siganus rivulatus. Aquac Res. 2015:46:928-36.

Schreck CB. Stress and rearing of salmonids. Aquaculture. 1982;28:241-9.

Simoes LN, Lombardi DC, Gomide ATM, Gomes LC. Efficacy of clove oil as anesthetic in handling and transportation of Nile tilapia, Oreochromis niloticus (Actinopterygii: Cichlidae) juveniles. Zoologia. 2011;28:285-90.

Summerfelt RC, Smith LS. Anesthesia, surgery, and related techniques. In: Methods for Fish Biology. Bethesda: American Fisheries Society; 1990. p. 213-72.

Tarkhani R, Imani A, Jamali H, Moghanlou KS. Anaesthetic efficacy of eugenol on flowerhorn, Amphilophus labiatus $\times$ Amphilophus trimaculatus. Aquac Res. 2016;1:1-9.

United States Food and Drug Administration. Scientific literature reviews of eugenol and related substances in flavour Usage. Washington: Flavour extract manufactures association of the United States; 1978. p. 1.

Ready to submit your research? Choose BMC and benefit from:

- fast, convenient online submission

- thorough peer review by experienced researchers in your field

- rapid publication on acceptance

- support for research data, including large and complex data types

- gold Open Access which fosters wider collaboration and increased citations

- maximum visibility for your research: over $100 \mathrm{M}$ website views per year

At BMC, research is always in progress.

Learn more biomedcentral.com/submissions 